OPEN ACCESS

Edited by:

Nicolas Dutzan,

University of Chile, Chile

Reviewed by:

Radostaw Mlak,

Medical University of Lublin, Poland

Seon Hee Chang,

University of Texas MD Anderson

Cancer Center, United States

*Correspondence:

Heather R. Conti

heather.conti@utoledo.edu

Specialty section:

This article was submitted to

Mucosal Immunity,

a section of the journal

Frontiers in Immunology

Received: 29 March 2021

Accepted: 31 May 2021

Published: 17 June 2021

Citation:

Saul-McBeth J, Dillon J, Lee A, Launder D, Kratch JM, Abutaha E,

Williamson $A A$, Schroering $A G$,

Michalski G, Biswas P, Conti SR III,

Shetty AC, McCracken C, Bruno VM,

Parsai El and Conti HR (2021) Tissue

Damage in Radiation-Induced Oral

Mucositis Is Mitigated by

IL-17 Receptor Signaling.

Front. Immunol. 12:687627.

doi: 10.3389/fimmu.2021.687627

\section{Tissue Damage in Radiation-Induced Oral Mucositis Is Mitigated by IL-17 Receptor Signaling}

\author{
Jessica Saul-McBeth ${ }^{1}$, John Dillon ${ }^{1}$, Aaron Lee ${ }^{2}$, Dylan Launder ${ }^{1}$, Jacqueline M. Kratch ${ }^{1}$, \\ Eanas Abutaha ${ }^{1}$, Alexandria A. Williamson ${ }^{1}$, Allen G. Schroering ${ }^{3}$, Grace Michalski ${ }^{1}$, \\ Priosmita Biswas ${ }^{1}$, Samuel R. Conti III ${ }^{1}$, Amol C. Shetty ${ }^{4}$, Carrie McCracken ${ }^{4}$, \\ Vincent M. Bruno ${ }^{4}$, E. Ishmael Parsai ${ }^{2}$ and Heather R. Conti ${ }^{1 *}$

\begin{abstract}
1 Department of Biological Sciences, University of Toledo, Toledo, OH, United States, ${ }^{2}$ Department of Radiation Oncology, Division of Medical Physics, The University of Toledo, Toledo, OH, United States, ${ }^{3}$ Department of Surgery, The University of Toledo, Toledo, OH, United States, ${ }^{4}$ Institute for Genome Sciences, University of Maryland School of Medicine, Baltimore, $M D$, United States
\end{abstract}

Oral mucositis $(\mathrm{OM})$ is a treatment-limiting adverse side effect of radiation and chemotherapy. Approximately $80 \%$ of patients undergoing radiotherapy (RT) for head and neck cancers (HNC) develop OM, representing a major unmet medical condition. Our understanding of the immunopathogenesis of $\mathrm{OM}$ is limited, due in part to the surprising paucity of information regarding healing mechanisms in the oral mucosa. RNAseq of oral tissue in a murine model that closely mimics human OM, showed elevated expression of IL-17 and related immune pathways in response to head and neck irradiation (HNI). Strikingly, mice lacking the IL-17 receptor (IL-17RA) exhibited markedly more severe OM. Restoration of the oral mucosa was compromised in $1 / 17 \mathrm{ra}^{-/-}$mice and components associated with healing, including matrix metalloproteinase 3, 10 and IL-24 were diminished. IL-17 is typically associated with recruitment of neutrophils to mucosal sites following oral infections. Unexpectedly, in OM the absence of IL-17RA resulted in excessive neutrophil recruitment and immunopathology. Instead, neutrophil activation was IL-1R-driven in $/ 17 \mathrm{ra}^{-/-}$mice. Blockade of IL-1R and depletion of neutrophils lessened the severity of damage in these mice. Overall, we show IL-17 is protective in $\mathrm{OM}$ through multiple mechanisms including restoration of the damaged epithelia and control of the neutrophil response. We also present a clinically relevant murine model of human $\mathrm{OM}$ to improve mechanistic understanding and develop rational translational therapeutics.

Keywords: oral mucositis (OM), inflammation, interleukin-17, oral mucosa, healing

\section{INTRODUCTION}

Oral mucositis $(\mathrm{OM})$ is one of the most common non-hematological side effects of radiotherapy (RT) and/or chemotherapy for head and neck cancers (HNC), characterized by tissue injury of the oral mucosae (1). OM is painful and associated with nutritional deficiency, thus resulting in a large economic burden due to costs and clinical risks associated with pain management and liquid diet supplementation (2). In the 100 days following the initial development of OM, the risk of mortality 
increases 3.9-fold (3). During OM the loss of oral mucosal integrity, imbalance of the oral flora and hyposalivation leads to increased susceptibility to oral infections, including oropharyngeal candidiasis (OPC) and herpes simplex virus (HSV), pronounced sensitivity to dental caries, gingivitis and periodontitis (3-5). The current therapeutic options for OM are largely ineffective and management relies on lessening symptoms, not prevention (6-9). Ultimately, severe OM can lead to increased hospitalizations and the use of feeding tubes, which may interrupt or alter cancer therapy leading to worse tumor outcomes $(2,6,10-12)$.

The stages of OM in both humans and mice include initiation, primary damage with signal amplification, ulceration, followed by healing and fibrosis $(2,13)$. Ionizing radiation initiates OM through toxicity to basal epithelial, submucosal, and endothelial cells $(3,14)$. Cells with extensive DNA damage produce reactive oxygen species (ROS) that accumulate in tissue (11). Injured cells also release damage-associated molecular patterns (DAMPs) that bind receptors to initiate inflammatory signaling cascades (12). Eventually, repair and healing occurs via signaling from the extracellular matrix (ECM) and anti-inflammatory cytokines (2). It is understood that the progression of $\mathrm{OM}$ requires activation of NF-kappaB which induces transcriptional expression of proinflammatory mediators, such TNF- $\alpha$, IL-1, and IL-6 $(2,11,15)$. Sustained expression of these cytokines perpetuates tissue damage, resulting in the loss of membrane integrity and development of oral ulcers (13). While the clinical progression of $\mathrm{OM}$ is described, the intricate signaling networks involved in the progression and resolution have not been fully elucidated ( 8 , $9,11)$. Indeed, there is a general paucity of information regarding the immunology of the oral mucosa, highlighting a need to better understand these processes.

Interleukin-17 (IL-17) is a proinflammatory cytokine that plays diverse roles in oral health and disease. For example, IL-17 is protective against acute bone loss caused by gingivitis-related bacteria (16). However, in chronic periodontitis, IL-17 promotes inflammation-induced bone loss (17). Furthermore, due to the proliferative and inflammatory properties of IL-17, it is implicated in tumorigenesis in several cancers, including esophageal cancer $(18,19)$. IL-17 also supports tongue squamous cell carcinoma formation $(20,21)$. In other tissue compartments, the roles for IL17 in damage and healing are not straightforward either. IL-17 protects the intestinal epithelium through maintenance of tight junctional proteins and stimulating epithelial cell proliferation (22, 23). Whereas, inhibition of IL-17 or IL-17RA leads to a weaker intestinal epithelial barrier and higher incidence of severe disease in the gut $(22,24)$. When considering the skin though, the proliferative capacity of IL-17 can be damaging during psoriasis, yet advantageous to tissue repair during injury, likely via similar effects on the epithelial layer (25-27).

Since IL-17 has distinct roles in tissue repair and maintenance it was important to determine how the cytokine functions during the severe ulceration associated with head and neck irradiation (HNI). We focused on whether IL-17RA was protective or pathogenic during oral damage and healing associated with radiation. We approached this by exposing $I l 17 \mathrm{ra}^{-/-}$mice to HNI-induced OM.
Here, we provide evidence that IL-17RA signaling is beneficial during $\mathrm{OM}$ by promoting tissue regeneration and unexpectedly dampening the neutrophil response. In the absence of IL-17RA, other mediators, including IL-1, were dysregulated leading to excessive inflammation and tissue damage. Overall, while IL-17/ IL-17RA are potential targets in HNC, care must be taken in establishing therapeutic strategies in patients who develop OM during radiation treatment.

\section{MATERIALS AND METHODS}

\section{Mice}

Mice were acquired by materials transfer agreement (MTA) with Amgen $\left(I l 17 \mathrm{ra}^{-/-}\right)$(28). In all experiments, age- and gendermatched littermate controls or WT controls (Jax Inc.) were used. All mice were housed with food and water ad libitum under a 12hour dark/light cycle in a specific pathogen-free facility at the University of Toledo. All animals were used in accordance with the protocol reviewed and approved by the Institutional Animal Care and Use Committee and in accordance with guidelines from the National Institutes of Health, the Animal Welfare Act, and U.S. Federal Law.

\section{Radiation-Induced OM}

To expose mice to HNI and induce OM, mice were immobilized using an anesthesia protocol approved by the Department of Laboratory Animal Research at the University of Toledo. Mice were aligned in a custom-made Polystyrene phantom with the aid of the University of Toledo Department of Radiation Oncology staff, using the Linear Accelerator's (Linac's) field light to assure only the head received radiation. A one $\mathrm{cm}$ tissue-mimicking super flab bolus material was used to assure the distribution of the dose at a $99-100 \%$ level was in the entire depth intended for treatment. This assured over $99 \%$ dose to the surface of the skin and at the distal depth which was on average $1.5 \mathrm{~cm}$. The energy used for this experiment was a $6 \mathrm{MeV}$ electron beam and monitor units were calculated to deliver 22.5 Gy at the rate of $1,000 \mathrm{cGy} / \mathrm{min}$ in a single fraction. Based on characteristics of the $6 \mathrm{MeV}$ electron profile and realizing that $50 \%$ isodose line was at the edge of the field, the mouse's head and tongue area received 80 to $85 \%$ of the nominal 22.5 Gy amounting to $18-19$ Gy. The effective delivered dose throughout this manuscript should then be taken as 80 to $85 \%$ of what is presented as the nominal dose. The custom manufactured jigs at the head of the Linac were used to align the body such that only the head was exposed, and the body protected from the radiation beam. Following irradiation, animals were removed from the jig, housed in a climate and light/dark controlled environment, and allowed free access to food and water. Animals were monitored daily for changes in weight and activity.

\section{Macroscopic and Histopathologic Examination}

Tongues were rinsed with PBS and stained with $1 \%$ toluidine blue for $2 \mathrm{~min}$, followed by washing with acetic acid for $30 \mathrm{~s}$ to reveal ulcerative lesions. The percentage of toluidine blue- 
positive areas was calculated using ImageJ software and \% damage quantified by the area of toluidine blue positive area/ surface area of whole tongue $* 100$. Tissues were formalin-fixed, paraffin-embedded, and sectioned at a thickness of $5 \mu \mathrm{m}$. Ulcer size, mucosal thickness, and cellular infiltrate were measured in H\&E-stained tissue using a Bio-Tek Cytation 5 automated microscope (Bio-Tek) and equipped with image-capturing software by The University of Toledo Advanced Microscopy \& Imaging Center (Toledo, $\mathrm{OH}$ ). Investigators analyzing staining of tongues were blinded to treatment and mouse cohort.

\section{Immunohistochemistry}

Tissues were formalin-fixed, paraffin-embedded, and sectioned at $5 \mu \mathrm{m}$. Slides were dehydrated with xylene and ethanol gradient, and antigen retrieval and blocking performed. Sections were further labeled with MPO (R\&D Systems, Minneapolis, MN) or ki67 (Cell Signaling Technology, Danvers, MA). Secondary biotinylated antibody was applied, and slides incubated at room temperature for $1 \mathrm{~h}$. Signals were detected using Sigma Fast tablets to make the DAB solution (Sigma Aldrich, St. Louis, MO) and the reaction stopped by placing slides in TBS. For IL-1 $\alpha$, MMP9, and TIMP2 IHC was performed on paraffin sections using avidin-biotin-peroxidase complex (streptavidin-biotin labeled method) with the Cell and Tissue staining kit (R\&D Systems, Minneapolis, MN). The manufacturer's protocol was followed. The antibodies for IL$1 \alpha$, MMP9, and TIMP2 were purchased from R\&D Systems, Inc. (Minneapolis, MN).

\section{ELISA}

Fresh or frozen $\left(-80^{\circ} \mathrm{C}\right)$ tongue tissue was submerged in cold sterile saline and homogenized by GentleMACS Dissociator (Miltenyi Biotec) in lysis buffer containing: $50 \mathrm{mM}$ potassium phosphate buffer $\mathrm{pH} 6.0$ and $0.5 \%$ HTAB. Samples were lysed further by $3 \times$ freeze thaw at $37^{\circ}$ and centrifuged at $10,000 \times g 4^{\circ}$ for $15 \mathrm{~min}$. Supernatants were collected and protein concentration determined by BCA (Thermo Fisher Scientific). Following protein determination, IL-1 $\beta$ was semi-quantitatively measured by enzyme-linked immunosorbent assay (R\&D Systems) according to manufacturer's protocol. Assay was performed in biological triplicate in technical duplicate.

\section{Complete Blood Count}

EDTA anti-coagulated blood samples from cardiac puncture were used to obtain a complete blood count with an insight V5 Hematology Analyser (Woodley Equipment, Bolton, Lancashire).

\section{Real-Time Reverse Transcription-PCR}

Total RNA was extracted using TRI reagent (Sigma-Aldrich, St. Louis, MO) and RNA (1 $\mu \mathrm{g})$ reverse-transcribed by HighCapacity cDNA RT kit (Thermo Fisher Scientific, Waltham, $\mathrm{MA}$ ) at $25^{\circ}$ for $10 \mathrm{~min}, 37^{\circ} \mathrm{C}$ for $120 \mathrm{~min}$, followed by $85^{\circ}$ for 5 min. Quantitative PCR was performed using PowerUp SYBR green Master Mix and a Quant Studio 3 detection system (Applied Biosystems, Waltham, MA), as specified by the manufacturer. The crossing point was defined as the maximum of the second derivative from the fluorescence curve. For quantification, we report relative mRNA expression of specific genes using the $2^{-\Delta \mathrm{CT}}$ method and used GAPDH housekeeping gene for normalization. Primers that were made in house are shown in Supplementary Table 1, otherwise primers were obtained from QuantiTect (QIAGEN, Germantown, MD). Assays were performed in biological triplicate in technical triplicate.

\section{RNA Sequence Analysis}

RNA-seq libraries (strand-specific, single end) were generated from total tongue RNA by using a NEBNext Ultra II Directional RNA Library Prep kit (New England BioLabs, Ipswich, MA). Fifty nucleotides of the sequence were determined from one end of each cDNA fragment using the HiSeq platform (Illumina). Sequencing reads were aligned to the UCSC (University of California, Santa Cruz) mouse reference genome (mm10, GRCm38.75) using HISAT (29), and alignment files were used to generate read counts for each gene. Statistical analysis of differential gene expression was performed using the DEseq package from Bioconductor (30). A gene was considered differentially expressed if the FDR value for differential expression was $<0.01$. The RNA-seq analysis was performed in biological triplicate.

Enrichment and pathway analyses of the differentially expressed genes were performed using the Upstream Regulator Analytic and the Diseases and Function analytic from the Ingenuity Pathway Analysis software (Ingenuity Systems; http://www.ingenuity.com). This software assesses the overlap between experimentally derived gene lists and an extensively curated database of target genes for each of several hundred known regulatory proteins and pathways. It then uses the statistical significance of the overlap and the direction of the differential gene expression to make predictions about activation or repression of pathways.

\section{Antibody Treatment in OM Model}

Doses of anti-IL-1R (anti-Ly6G (BioXcell), and anti-G-CSF (R\&D Systems) neutralizing antibodies were based on previous studies (31-33). Isotype control antibodies dose and administration schedules are included (Supplementary Table 2). Mice were treated i.p. on days $0,2,4,6$, and 8 of the experiment with antibodies directed against IL-1R (300 $\mu \mathrm{g} /$ mouse or IgG isotype control (BioXcell) (300 $\mu \mathrm{g} / \mathrm{mouse})$, in age- and sex-matched controls. For the anti-Ly6G (150 $\mu \mathrm{g} /$ mouse) and anti-G-CSF (10 $\mu \mathrm{g} /$ mouse) mice were treated i.p. with both antibodies and controls (R\&D Systems) on d7, followed by daily treatments of G-CSF on d8, 9, and 10 of the experiment. Mice were treated with $\alpha$-IL-17A or isotype control (BioXcell) at a $150 \mu \mathrm{g} /$ mouse on days 8 and 10 post irradiation. On day 11 following HNI, tongues were harvested and assessed for tongue damage by toluidine blue+ staining.

\section{Flow Cytometry}

Tongue tissue was mechanically homogenized in RPMI 1640 media then incubated at $37^{\circ} \mathrm{C}$ for $42 \mathrm{~min}$ on a GentleMACS Dissociator (Miltenyi Biotec) using tissue dissociation kits (Miltentyi Biotec). Resulting solution was passed through a cell 
strainer for single-cell suspensions. After brief centrifugation, cells were reconstituted with PBS supplemented with 2\% FBS and $2 \mathrm{mM}$ EDTA. Some $2 \times 10^{6} / \mathrm{ml}$ viable cells were obtained by staining with Trypan blue and counting on a hemocytometer. For analysis of immune cells, an initial incubation of CD16/ CD32 Fc Block (BD Biosciences) was followed by staining with the following antibodies, all from BioLegend (San Diego, CA): CD11b-PerCP/Cyanine5.5 (M1/70), GR-1-APC (RB6-8C5), F4/ 80-APC/Cyanine7 (BM8), and I-A/I-E-BV510 (M5/114.15.2).

For analysis of apoptosis, separate cell suspensions were reconstituted in Annexin $\mathrm{V}$ Binding Buffer followed by incubation with Annexin V-PE/Cy7 antibody and Propidium Iodide (Biolegend, San Diego, CA), for $10 \mathrm{~min}$ before flow cytometric analysis. Flow cytometry was performed on an LSRFortessa (BD Bioscience, San Jose, CA) and analyzed with FlowJo (BD Bioscience, San Jose, CA). For flow analysis lymphocyte and myeloid populations were gated out, and the resulting epithelial cell populations were further analyzed (Supplementary Figure 3).

\section{Data Analysis}

Data was analyzed on Prism (Graphpad V8.4.3). ELISA data is presented as one-way ANOVA with Tukey's post hoc analysis. Flow cytometry was analyzed by day with Student's $t$ test and is presented as the mean \pm SEM. Tongue damage data is presented as geometric mean \pm SEM and analyzed by ANOVA with Tukey's post hoc analysis or Student's $t$ test for analysis between two groups. PMN quantification was analyzed by ANOVA with Tukey's post hoc analysis. Gene expression data is presented as mean \pm SEM analyzed by Kruskal-Wallace test with Dunn's multiple comparisons or ANOVA with Tukey's post hoc analysis. Normality was evaluated via Shapiro-Wilk tests. Each symbol represents one mouse unless indicated. ${ }^{\star} P<0.05$, ${ }^{* *} P<0.01$, ${ }^{* * *} P<0.001$, and ${ }^{* * *} P<0.0001$.

\section{RESULTS}

\section{HNI Induces an IL-17-Related Transcriptional Profile During OM}

Sensitivity to $\mathrm{OM}$ is dependent on many factors including treatment type, dose rate, total dose, and volume irradiated. Most patients with HNC are treated with external beam radiotherapy using a relatively newer modality known as Intensity Modulation Radiotherapy (IMRT). This can only be implemented using complex treatment planning algorithms that can account for behavior of primary and scatter radiation in areas of heterogeneity $(34,35)$. In addition, these treatment planning systems contain optimization routines for inverse planning to achieve optimal dose to the target volume while sparing normal tissue. All of these newer features have been instrumental in reducing the severity of OM in recent years, but we still consider this as a major side effect of radiation for HNC patients that needs to be dealt with (35). In order to model OM, we used a single-dose of radiation targeting the head and neck regions of mice using a clinical linear accelerator capable of
IMRT delivery. To define the stages of OM through healing, mice were irradiated and tongue tissue harvested daily for 13 days (Figure 1A). Irradiated mice presented with symptoms typically associated with human OM, including damage and overt lesions on the tongue. A dose of $22.5 \mathrm{~Gy}$ caused damage to the oral mucosa that was evident on Day 8 ( $\sim \%$ of tissue toluidine blue+), peaked on Day 11 ( $23 \%$ of tissue, with complete healing by Day 15 ( $0 \%$ of tissue), which is similar to the stages of OM in humans $(8,36,37)$ (Supplementary Figure 1A). In order to understand the immune components responsible for signal amplification and ulceration in the tongue tissue during OM, we performed RNA sequencing (RNA-Seq) analysis of mRNA from tongue tissue of non-irradiated sham mice and mice exposed to $22.5 \mathrm{~Gy}$, harvested on Day 11 during peak damage $(n=3)$. The sequencing profiles showed that 988 genes exhibited a change in expression (FDR $<0.01$ ) in at least one of the HNI versus sham comparisons (Supplementary Tables 3, 4). Next, we used Ingenuity Pathway Analysis (IPA) to identify pathways activated during OM. Processes involved in epithelial cell survival and proliferation were enriched during peak damage. The most differentially expressed genes were also involved in immune functions such as global recruitment of immune cells $\left(\mathrm{p}=2 \times 10^{-18}\right)$, movement of polymorphonuclear cells $(\mathrm{PMNs})\left(\mathrm{p}=4 \times 10^{-11}\right)$, and development of Th17 cells $\left(\mathrm{p}=4 \times 10^{-6}\right)$ (Figure 1B).

Further analysis of genes differentially expressed in mice with OM showed many immune components related to the IL-17 signaling pathway were activated after $\mathrm{HNI}$, with stronger induction in the distal portion of the tongue where damage predominated (Figure 1C and Supplementary Figure 1B). These targets included chemokines, cytokines, signaling molecules, AMPs, and proteases that are regulated by IL-17RA in the context of other diseases (38). Since IL-17-related genes were induced during peak damage, we next determined the expression kinetics of both Il17a and Il23a throughout the stages of OM. After HNI, Il23a expression peaked on Day 7 followed by a rapid loss of expression by Day 9. Induction of Il23a was followed by Il17a expression, which was detected after Day 9 and increased by Day 11, the time point at which WT mice presented with severe ulcerative damage. The levels of $1117 a$ dropped by Day 12 as healing commenced (Figure 2A). Taken together these data indicate that the IL-23/IL-17 pathway is activated following HNI, and IL-23 expression preceding IL-17 is predicted, as it is understood to be upstream of IL-17 production.

\section{IL-17RA Signaling Protects Against Ulcerative Damage and Epithelial Loss Following HNI}

In order to determine if IL-17RA is protective or pathogenic during the most severe phase of OM, WT and $1117 \mathrm{ra}^{-/-}$mice were subjected to HNI and damage assessed. Larger ulcerative lesions were detected in $1117 \mathrm{ra}^{-/-}$mice ( $11 \%$ of tongue) on Day 11 compared to WT mice ( $\sim 5 \%$ of tongue) (Figures $2 B, D$ ). In addition to the increased surface area of damage in the $1117 \mathrm{ra}^{-1-}$ mice (Figure 2E), lesions were deeper $(1.8 \mathrm{~mm} v s .0 .6 \mathrm{~mm})$ and the adjacent tissues were thinner $(0.5 \mathrm{~mm}$ vs. $1.7 \mathrm{~mm})$ than those in WT mice during peak damage (Day 11) (Figure 2F). Next, we 
A

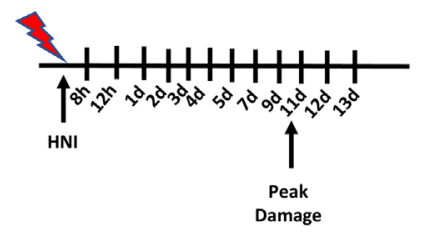

B

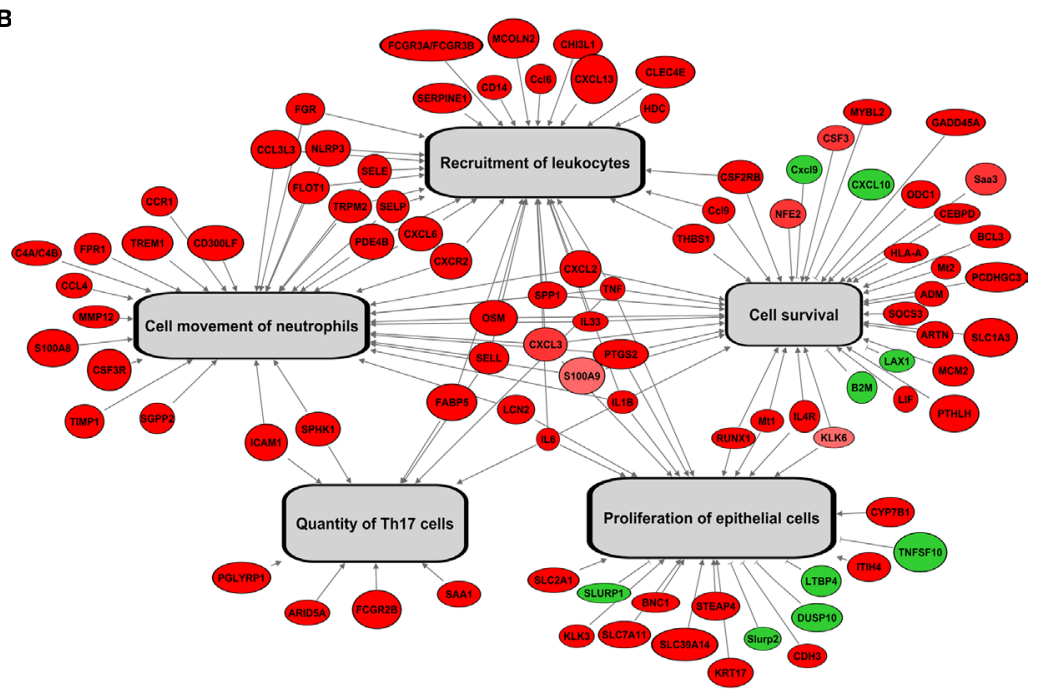

C

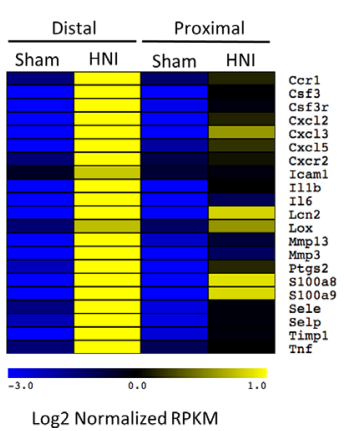

FIGURE 1 | Targeted HNI induces OM in mice. (A) Model of HNI-induced OM. Mice received no radiation (sham) or HNI on DO, and tongues were harvested at various time points. (B) Schematic analysis of select biological functions predicted to be activated in response to HNI. Genes colored in red have HNI-induced expression and genes labeled in green have HNI-repressed expression. Gray arrows depict biological functions that are predicted by our analysis to be activated. (C) Comparison of IL-17RA regulated genes between sham and irradiated mice in the distal portion of the tongue.

treated mice with $\alpha$-IL-17A or mouse IgG1 isotype control to determine if therapeutic blockade of IL-17 rendered mice more susceptible to OM. There were no differences in damage between mice treated with $\alpha$-IL17A or $I l 17 \mathrm{ra}^{-/-}$mice (Figure 2C). Based on these findings, IL-17A/IL-17RA appear protective in HNIinduced damage to the oral mucosa.

\section{IL-17RA Promotes Cell Survival and Proliferation During OM}

To elucidate the mechanism of IL-17RA-mediated protection, we next determined the role of IL-17 signaling in epithelial repair of the oral mucosa after radiation. Epithelial proliferation contributes to the rate of healing during OM, which is partly dependent on epidermal growth factor (EGF) and keratinocyte growth factor (KGF) (8). While expression of Egf was comparable between $1117 \mathrm{ra}^{-/-}$and WT mice regardless of radiation exposure, markers for early differentiated epithelial cells, keratin-15 (Krt15) and keratin-16 (Krt16), were reduced in $\mathrm{Ill}_{\mathrm{ra}} \mathrm{ra}^{-/}$mice, as was $\mathrm{Kgf}$ (Figure 3A), signifying a lack of reepithelialization (39). Similarly, expression of $C d c 3 a$, which is essential for cytokinesis, was reduced in $1117 \mathrm{ra}^{-/-}$mice. Furthermore, Ki67 staining in tongue tissue revealed fewer dividing cells in the basal stem cell layer of irradiated $1417 \mathrm{ra}^{-/-}$ mice (two cells/field of view) compared to WT mice (40 cells/ 
A

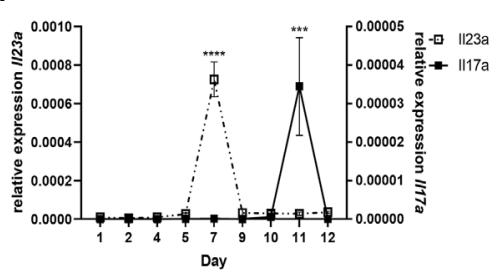

B

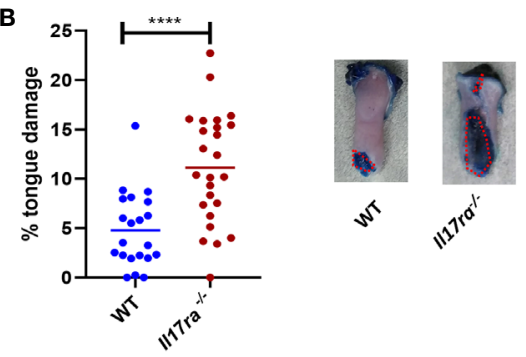

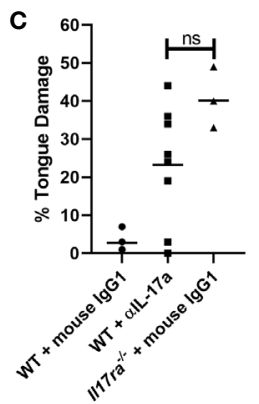

D

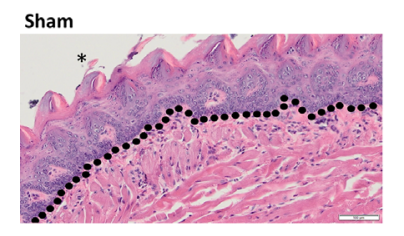

WT-HNI

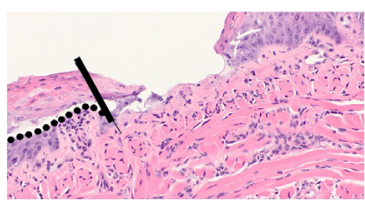

$\| 17 \mathrm{ra}^{-/-}-\mathrm{HNI}$

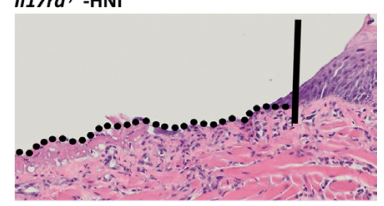

E
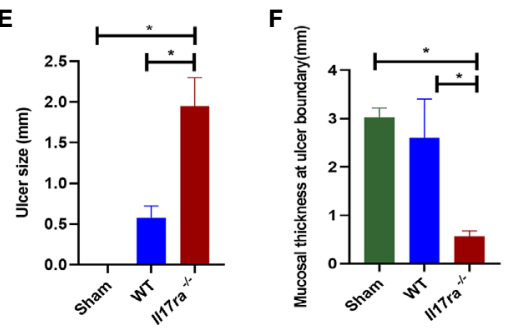

FIGURE 2 | IL-17 is induced and is protective following HNI (A) Expression kinetics of II23 and I/17a following HNI assessed by qPCR. Results pooled from at least three experiments analyzed by ANOVA with Tukey's post hoc. (B) Quantification of toluidine blue staining by determining the surface area of the tongue positive for blue staining compared to the total surface area of tongue on each mouse on day 11 post radiation. The staining on the ventral side of the tongue was not included in the quantification since this included the excision site. Red dotted lines represent the surface area of a lesion as determined for all tongues. Data pooled from at least three experiments. Analyzed by Student's $t$ test. (C) Mice were treated on days 8 and 10 with $\alpha$-IL-17A or mouse lgG1 (150 $\mu g$ ) and damage quantified on day 11 ( $n$ = at least three per group). Control animals received appropriate isotype controls (Supplementary Table 2). Tongue damage analyzed by ANOVA with Tukey's. (D) Hematoxylin-eosin staining of mouse tongues D11 following radiation. Asterisk denotes papillae. The vertical lines in the images of tongues highlight the ulcer boundary and the dotted lines represent the epithelial-stromal boundary. (E, F) Quantification of lingual ulcer size and mucosal thickness (N= at least 5 per group). Data represents as least three pooled experiments. Analyzed by ANOVA with Tukey's post hoc. Scale bars: $50 \mu \mathrm{M}$. Data shown as means $\pm \mathrm{SEM}$, ( ${ }^{\star} \mathrm{P}<0.05$, ${ }^{\star \star \star} \mathrm{P}<0.001$, ${ }^{* \star \star *} \mathrm{P}<0.0001$. NS is not significant.

field of view) (Figure 3B). Also, the number of Ki67+ cells in irradiated WT mice was not significantly different compared to WT sham controls (59 cells/field of view). Consistently, transcript levels of components normally expressed during the healing process (Mmp3, Mmp10, Sprr2b and Il24) were highly induced in WT mice during OM, but were all reduced in $\mathrm{Ill}_{7 \mathrm{ra}^{-/-}}$ mice (Figures 3A, 5A, Supplementary Figure 2). IL-24 production in the suprabasal region of the tongue tissue was undetectable in Ill1 $\mathrm{ra}^{-/-}$mice compared to WT mice (Supplementary Figure 2A). In addition, a major cytotoxic effect of RT is activation of apoptosis and necrosis in the proliferating basal cell layer. Relatedly, Ill $7 \mathrm{ra}^{-1-}$ mice had more necrotic and early/late apoptotic oral mucosal cells on Days 9 through 11 compared to WT mice (Figure 3C). In all, suppression of these contributors to the healing process in the 

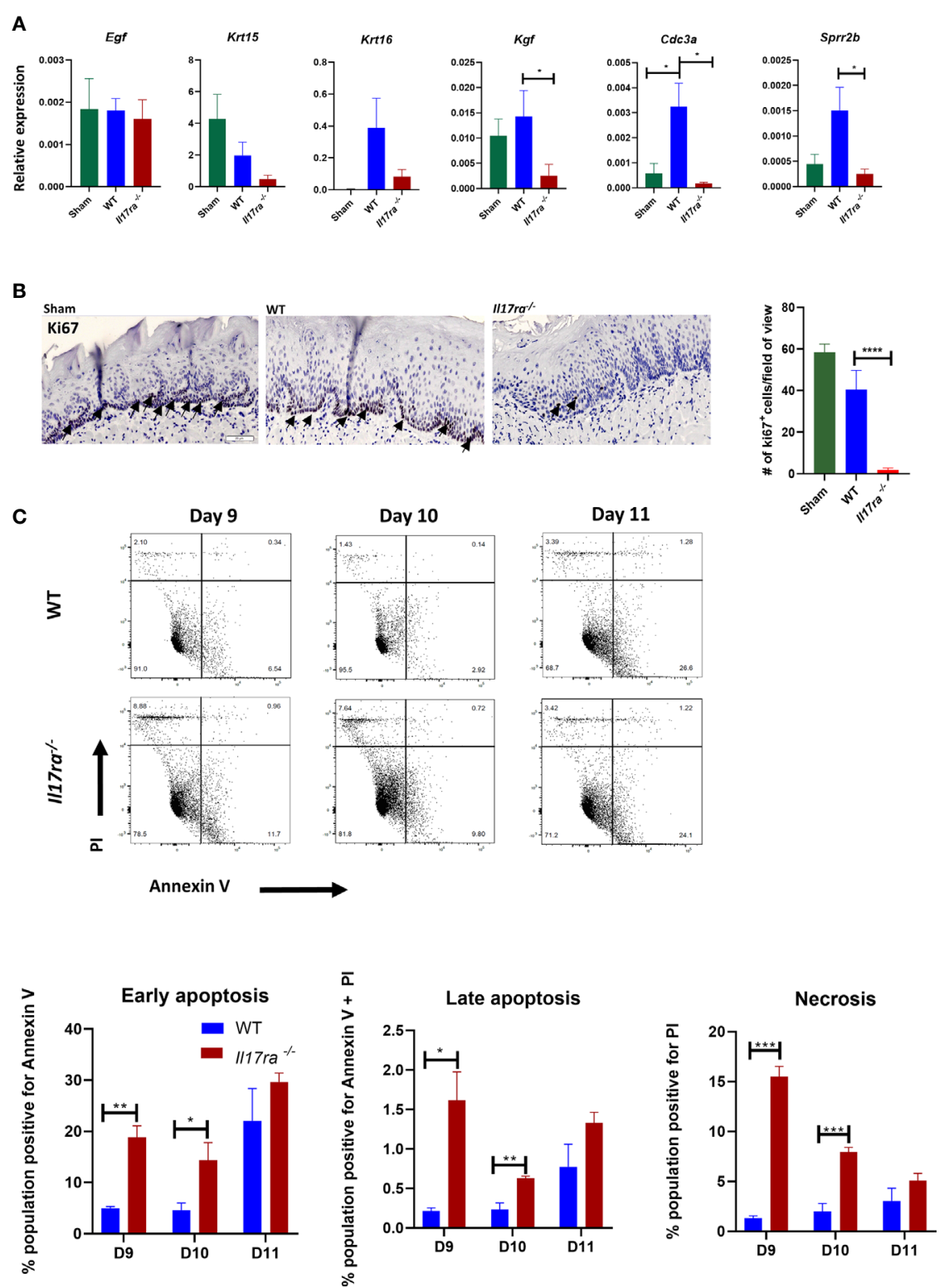

FIGURE 3 | In the absence of IL-17RA there is enhanced apoptosis and reduced proliferation (A) Expression differences relative to GAPDH of genes related to healing. $\mathrm{N}=$ at least five mice/group. Kgf and Cdc3a analyzed by Kruskal-Wallace with Dunn's multiple comparisons test, Sprr2b analyzed by ANOVA with Tukey's. Data pooled from at least three experiments (B) Proliferation marker Ki-67 staining and quantification in the dorsal portion of the tongue obtained on day 11 following radiation. Scale bar, $100 \mu \mathrm{M}$. Arrows represent positive Ki67 staining. Analysis of staining by ANOVA with Tukey's. (C) Apoptotic and necrotic cells analyzed by flow cytometric analysis after Annexin $\mathrm{V}$ and PI staining. Data representative of two independent experiments and analyzed by Student's $t$ test between days. Data shown as means $\pm \mathrm{SEM},\left({ }^{\star} \mathrm{P}<0.05,{ }^{* \star} \mathrm{P}<0.01,{ }^{* \star *} \mathrm{P}<0.001,{ }^{* \star \star *} \mathrm{P}<0.0001\right)$.

absence of IL-17RA further substantiates the importance of the receptor in protection and restoration of the oral mucosa during HNI-induced OM.

\section{Enhanced Neutrophil Response in IL-17RA-Deficient Mice}

In most disease contexts IL-17 does not act on granulocytes directly, but rather promotes neutrophil recruitment through the induction of chemokines including CXCL1, CXCL2 and CXCL5 and growth factors such as G-CSF in target non-hematopoietic cells. In the oral cavity specifically, mice lacking IL-17RA in the suprabasal oral mucosae $\left(I l 17 \mathrm{ra}^{\text {flfl }}-\mathrm{K} 13 \mathrm{Cre}^{+}\right)$have diminished neutrophil levels, contributing to their high susceptibility to oral candidiasis (40). We set out to determine if mice lacking IL17RA had the same neutrophil defects during OM caused by RT.

In patients receiving RT or chemotherapy, the early stages of $\mathrm{OM}$ are characterized by neutropenia, and a lack of circulating neutrophils can be a readout for OM severity (41-43). 
Neutrophils detected in the oral lesion later during the ulceration phase are generally thought to cause damage. The number of neutrophils also increases as microbes gain access to the submucosa, due to loss of barrier integrity $(43,44)$. By day 11 post-HNI, WT mice had levels of circulating neutrophils comparable to sham mice (Figure 4A), suggesting that irradiated mice were not neutropenic at this point. In contrast, the levels of blood neutrophils were elevated in $1 l 17 \mathrm{ra}^{-/-}$mice. Next, we assessed if neutrophils were recruited to the tongue. Compared to sham, WT and $I l 17 \mathrm{ra}^{-/-}$mice had comparable elevated levels of neutrophils in the whole tongue, indicating irradiation induces a neutrophil influx into the tissue at later stages of $\mathrm{OM}$, and this recruitment was surprisingly independent of IL-17RA signaling (Figure 4B). We then determined if neutrophils/polymorphonucler cells (PMNs) were localizing to ulcers in the absence of IL-17RA (Figure 4C). Unexpectedly again, $I l 17 \mathrm{ra}^{-/-}$mice showed significantly more PMNs migrated into the damaged lesions compared to WT mice. While expression of Cxcl1 and $\mathrm{Cxcl} 2$ were not affected (Figure 4D), there was a notable increase in Csf3 (encodes for G-CSF) in

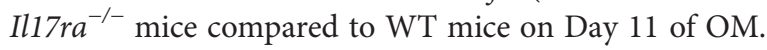

Since neutrophil recruitment is normally compromised in mice deficient in IL-17RA we next asked if the neutrophils in the lesion were functionally competent in $I l 17 \mathrm{ra}^{-/-}$mice. We measured myeloperoxidase (MPO) levels in tongue, a parameter also commonly used to assess the severity of $\operatorname{OM}(8,45,46)$. The oral mucosa of irradiated $1117 \mathrm{ra}^{-/-}$mice had greater MPO production compared to irradiated WT mice on Day 11 aligning with the increased presence of neutrophils in $1117 \mathrm{ra}^{-/-}$ mice (Figure 4E).

Neutrophils also activate MMPs through production of elastase $(47,48)$, so we reasoned that elevated neutrophil-mediated inflammation observed in the $I l 17 \mathrm{ra}^{-/}$mice could be due to dysregulated MMPs and could impact the process of wound healing $(49,50)$. The increased levels of $M m p 10$ and $M m p 3$ in the WT tissue during OM were diminished in the $1717 \mathrm{ra}^{-/-}$tissue (Figure 5A). In contrast, $M m p 9$, and $M m p 12$ transcripts were elevated, as well as MMP9 protein in the $I l 17 \mathrm{ra}^{-/-}$mice compared to sham and irradiated WT mice (Figures 5A, B). The skewed expression of MMPs was associated with a decrease in expression of MMP inhibitors, Timp1, Timp2, Timp3, and Timp4, and lower TIMP2 production in the $1117 \mathrm{ra}^{-1-}$ mice (Figures $5 \mathrm{C}, \mathbf{D}$ ). Collectively, these data indicate that during OM, IL-17RA is not necessary for neutrophil recruitment as it is in other disease settings, nor is IL-17 signaling involved in promoting neutrophil function. Moreover, in the absence of IL-17RA there is a disruption in the balance of inflammatory mediators leading to aggravated inflammation. This further substantiates that IL-17RA signaling is required for dampening the inflammatory response during HNI-induced OM.

\section{IL-1 Contributes to Neutrophil Accumulation in the Absence of IL-17RA}

Since neutrophils were still recruited into the OM lesion even in the absence of IL-17RA, we next determined what inflammatory mediators were responsible for the enhanced neutrophil response in the $I l 17 \mathrm{ra}^{-/-}$mice. In WT mice both Illa and Il1b are induced post-HNI (Supplementray Figure 2C) In the $I l 17 \mathrm{ra}^{-/-}$mice there were elevated transcript and protein levels of both IL- $1 \alpha$ and IL- $1 \beta$ on Day 11 (Figures 6A, B). Since both IL- $1 \alpha$ and IL- $1 \beta$ are implicated in the pathology of OM, and IL$1 \alpha$ at least partially regulates neutrophils in other oral diseases $(33,51-53)$, we asked if blocking IL-1R in WT and $1117 \mathrm{ra}^{-1-}$ mice would account for the increased damage when IL-17RA is lacking. Following $\alpha$-IL-1R Ab administration, OM damage was decreased in WT $(\sim 1.8$-fold reduction $)$ and $1117 \mathrm{ra}^{-/-}$mice ( $\sim 1.3$-fold reduction) compared to mice administered hamster IgG isotype control Abs (Figure 6C). Of note, the mice that received isotype control Abs had 3-fold higher damage compared to radiated mice that did not receive control Abs. This may be due to species specificity, antibody concentration or the dosing schedule since mice that received mouse IgG1 control Ab at a lower dose and less frequently did not present with increased tongue damage (Figure 2C and Supplementary Table 2). Even though mice treated with hamster IgG control antibody showed increased damage in the oral mucosa after radiation it was not related to elevated neutrophil numbers within the area of ulceration (Figure 6D). Yet, in irradiated $\mathrm{Il17ra}^{-/-}$mice the lessening of overt damage when IL-1R was blocked correlated with a decrease in neutrophils in the areas of ulceration (Figure 6D). This substantiates that when IL-17RA signaling is missing uncontrolled production of IL-1 is at least partially responsible for the increased damage and enhanced neutrophil response, and that $\alpha-I L-1 R$ is a viable treatment option to explore in OM.

\section{Neutrophil Blockade Accounts for the Excess Damage in the Absence of IL-17RA}

To further establish the pathogenic consequence of an elevated neutrophil response in the absence of IL-17RA we used a combination $\alpha-$ Ly6G and $\alpha-\mathrm{G}-\mathrm{CSF}$ or rat IgG2a and goat IgG isotype controls in WT and $I l 17 \mathrm{ra}^{-1-}$ mice (33). As in the IL-1R blockade study (Figure 6C), rat IgG2a and goat IgG administration resulted in increased damage compared to irradiated untreated mice, and again this higher damage was not related to an increased neutrophil influx (Figure 7B). Yet, $\alpha-$ Ly6G/G-CSF treatment resulted in the depletion of the excess neutrophils in $1117 \mathrm{ra}^{-/-}$mice (Figure 7B). This was associated with a reduction in tongue damage of around 2.5-fold (Figure 7A) and lower MPO activity (Figure 7C). The OM damage in WT mice was unaffected though following neutrophil depletion compared to mice that received isotype control Abs using this particular method and dosing schedule. Collectively these data suggest that IL-17RA is critical for modulating the neutrophil response during HNI, and in the absence of IL-17RA, IL-1-mediated neutrophil accumulation exacerbates inflammation and is detrimental to healing (Figure 7D).

\section{DISCUSSION}

While robust models exist to study damage in the skin, highly tractable systems to study injury of the oral mucosa have been lacking. Infections that breech the mucosal barrier in the oral 
A

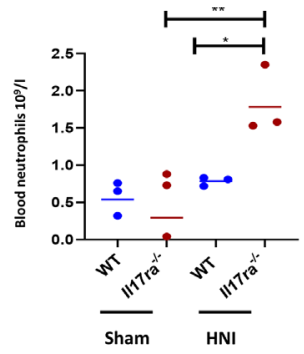

C sham

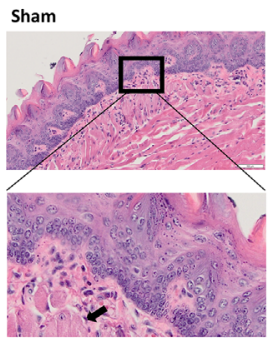

WT

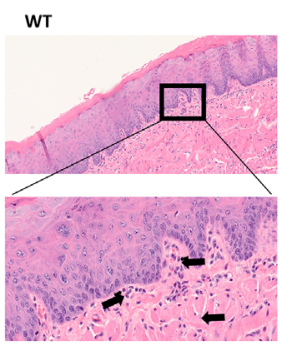

B

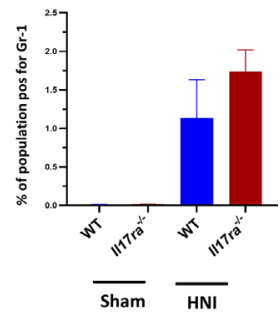

$1117 \mathrm{ra}^{-1}$
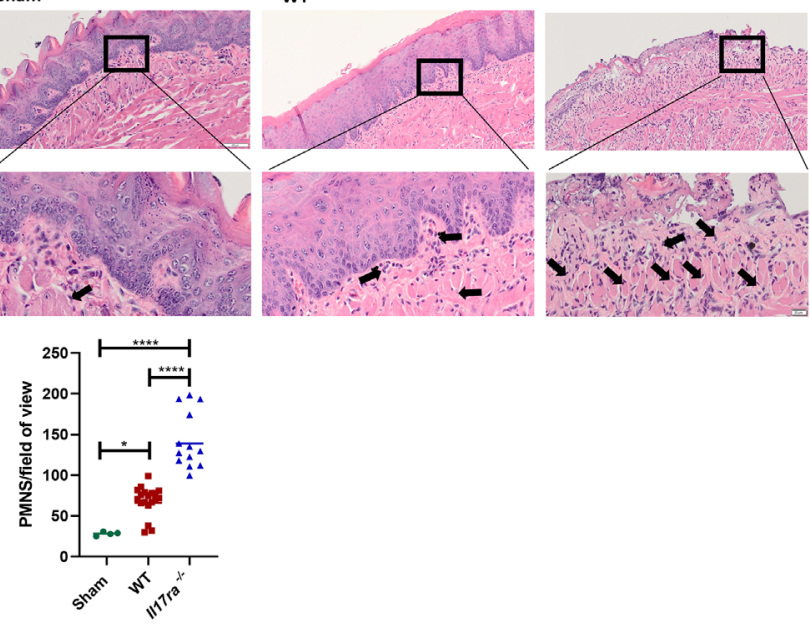

D

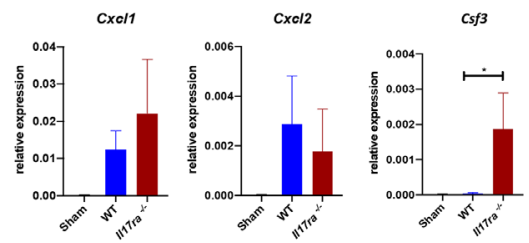

E

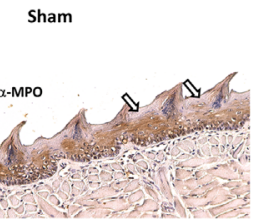

WT

$117 \mathrm{ra} \%$
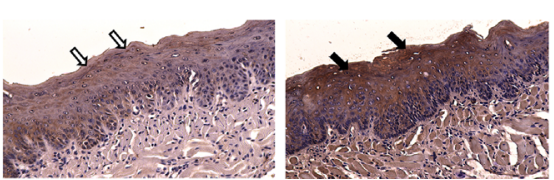

FIGURE 4 | Neutrophil recruitment to the tongue tissue is heightened in the absence of IL-17RA. (A) Cardiac puncture was performed to harvest blood from nonirradiated and irradiated mice and number of circulating neutrophils measured on D11. Data is representative of two independent experiments and analyzed by ANOVA with Tukey's. (B) Tongues harvested on day 11 and neutrophil (Gr1+) populations analyzed by flow cytometric analysis and ANOVA with Tukey's. Data representative of two independent experiments (C) Staining by hematoxylin and eosin of sectioned tongues and quantification of neutrophils on day 11 following HNI. Arrows represent positive neutrophil staining in distal tongue at ulcer boundary ( $\mathrm{N}=$ at least three tongues per group). Scale bar $100 \mu \mathrm{M}$ (top row) and $20 \mu \mathrm{M}$ (bottom row). Neutrophil quantification analyzed by ANOVA with Tukey's post hoc. (D) Expression of neutrophil chemokines relative to GAPDH on D11 ( $\mathrm{N}=3-5$ per group). Cxcl1 analyzed by ANOVA with Tukey's post hoc, Cxc/2 and Csf3 analyzed by Kruskal-Wallace and Dunn's multiple comparisons. Data pooled from at least three experiments. (E) Representative MPO-staining of ulcer boundary counterstained with hematoxylin. The filled arrow indicates positive MPO staining, while the

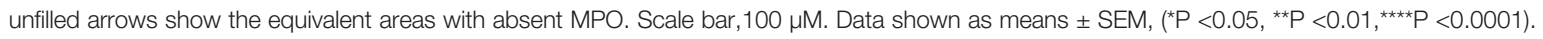

cavity require healing and restoration of the epithelium, but the injury is not as easily followed to the healing phase (54). To understand the immune components involved in repair processes in the oral mucosa, a model with a strong readout of damage (i.e. severe ulceration) that heals with predictable kinetics is required. We used a single dose of radiation that allowed for the development of OM that could be assessed visually and histologically, but also allowed procedural ease when using a clinical linear accelerator.

In general the pathogenesis of $\mathrm{OM}$ is similar between mice and humans (8). In patients, OM lesions can be detected on most keratinized tissues in the mouth that are exposed to radiation, including the tongue, buccal mucosa and the soft palate. Interestingly, overt damage was localized to the distal portion 


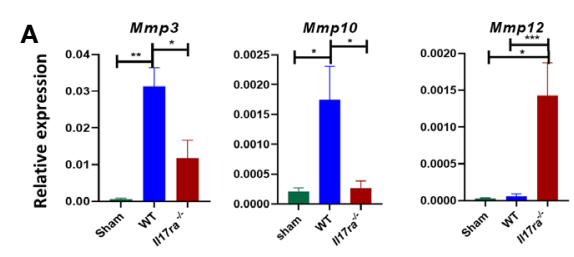

B
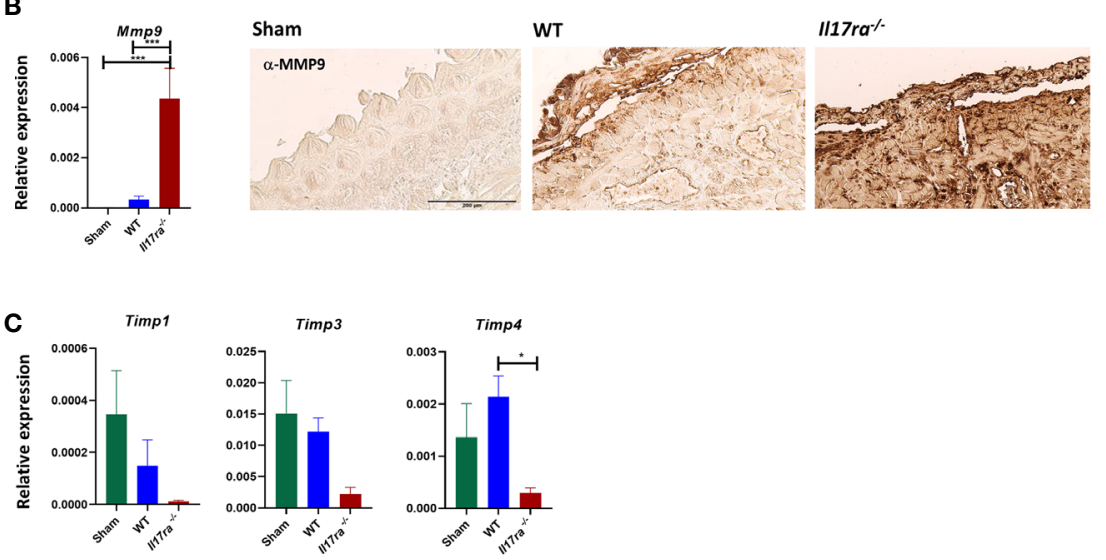

D
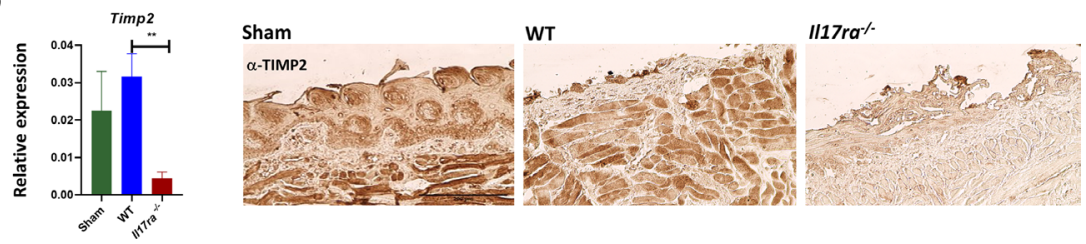

FIGURE 5 | The absence of IL-17RA is associated with dysregulated proteases and inhibitors. (A, C) Gene expression relative to GAPDH of proteases and inhibitors on D11 ( $\mathrm{N}=3-5$ per group). $\mathrm{N}=$ at least five per group. Mmp3 and Mmp10, and Timp1,2,3,4 analyzed by ANOVA with Tukey's post hoc, Mmp12 analyzed by Kruskal-Wallace and Dunn's multiple comparison test. Data pooled from at least 3 experiments. (B, D) IHC for MMP9 and TIMP2 from the ulcer boundary zone in the distal tongue. Scale bar, $200 \mu \mathrm{M}$. Data shown as means \pm SEM, $\left({ }^{\star} \mathrm{P}<0.05,{ }^{* \star} \mathrm{P}<0.01,{ }^{\star \star *} \mathrm{P}<0.001\right)$.

of the tongue in all mice (Supplementary Figure 1B). Also, IL17RA-related gene targets were more strongly activated where the lesions predominated in WT tongue, and we postulate this is the region of the tissue that requires $\mathrm{IL}-17$ to heal properly (Supplementary Figure 1B). The location of damaged tissue in the mouse could be an artifact of the way the mice are arranged in the apparatus of the linear accelerator or how the head and neck region is being exposed to radiation. In addition, the architecture of the mucosal surfaces in the oral cavity do vary between mice and humans, evidenced by distinct keratinization and cellular distribution patterns, which may explain the distribution of lesions in mice (55). We also have to consider the distribution of the cytokine receptors throughout the supraand sub-basal epithelial layers of the oral mucosa. While IL17RA is expressed ubiquitously, it is the expression of IL-17RA in the supra-basal epithelia that is required for protection from OPC (56), whereas mice deficient in IL-17RA specifically in the superficial epithelia $\left(I l 17 R A^{\mathrm{fl} / \mathrm{fl}}-\mathrm{K} 13^{\mathrm{Cre}}\right.$ ) are as susceptible to OPC as IL-17RA knockout mice. Therefore, follow-up studies using tissue-specific knockout mice are justified and will start to dissect these relationships.
IL-17 is highly expressed in ulcerated areas in a WT mouse and the overall effect of IL-17RA-signaling is beneficial during OM since $I l 17 \mathrm{ra}^{-/-}$mice showed considerably more damage. This is not the role attributed to the cytokine in other forms of recurring oral ulcers associated with leukocyte adhesion deficiency type 1 (LAD1), where both IL-23 and IL-17 are pathogenic (57). Now we establish that IL-17RA is necessary post-irradiation for maintaining the epithelial barrier through modulation of proapoptotic factors, while promoting effector molecules involved in cell survival and proliferation. This is similar to how IL-17RA helps maintain barrier integrity in the gastrointestinal tract (23). Furthermore, a striking phenotype of the $1117 \mathrm{ra}^{-/-}$mice was an unexpected increase in neutrophils found at the site of ulceration compared to WT mice 11 days post-irradiation. Normally IL-17 promotes an influx of neutrophils that is either protective or pathogenic depending on disease context through induction of neutrophil chemokines CXCL1,2 and 5 and growth factors such as G-CSF (58). In this way, mice deficient in IL-17 signaling components $\left(I l 17 a^{-/-}, I l 17 \mathrm{ra}^{-/-}, \mathrm{Act}^{-/-}\right.$etc.) are particularly sensitive to infections in which prevention is dependent on the action of neutrophils, such as oral candidiasis (59). Inversely, these 
A

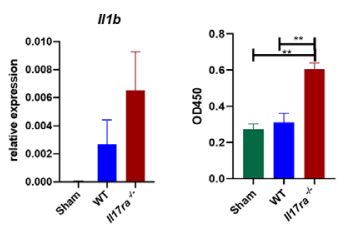

B

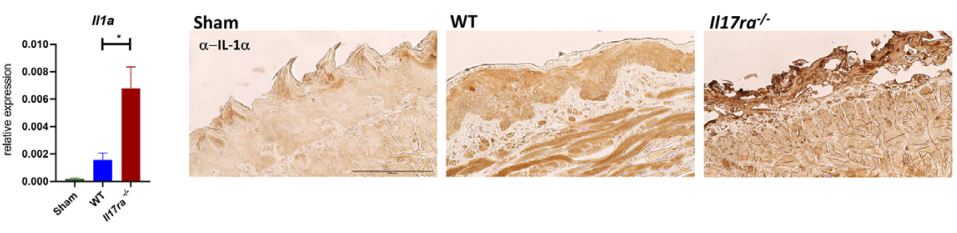

C

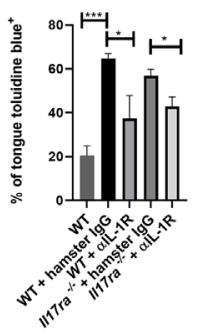

D
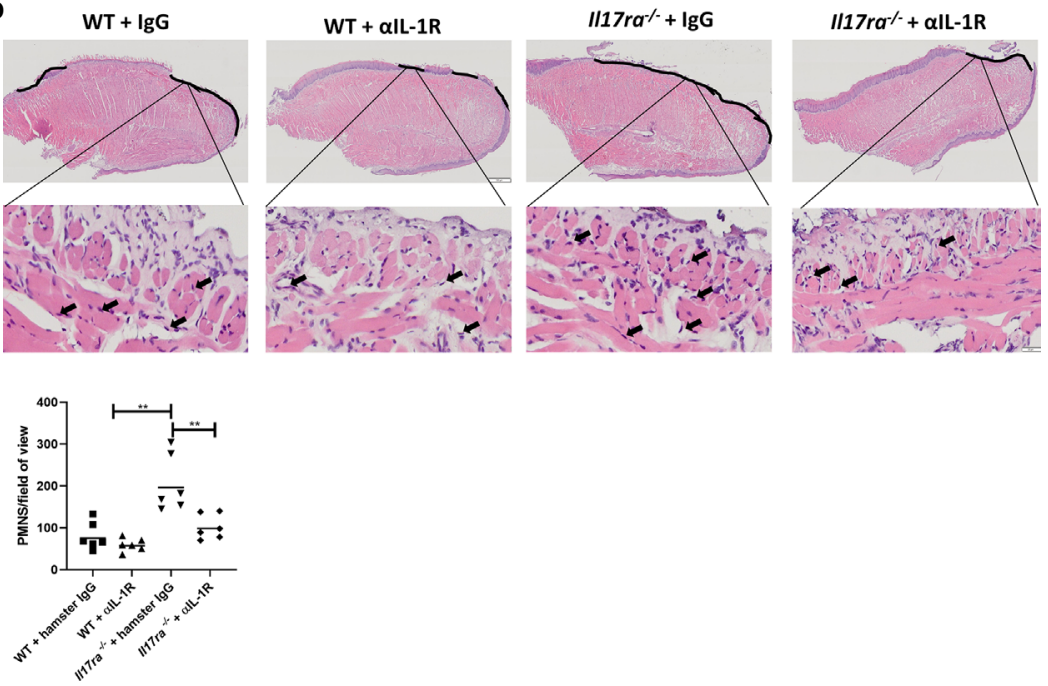

FIGURE 6 | Neutralization of IL-1R alleviates damage in the absence of IL-17RA. (A) Gene expression and circulating levels of IL-1 $\beta$ both analyzed by ANOVA with Tukey's. For gene expression data pooled from at least three experiments. Protein expression represents one experiment. (B) Gene expression and IHC of IL-1 $\alpha$ pooled from at least three independent experiments. Scale bar, $100 \mu \mathrm{M}$. Analyzed by ANOVA with Tukey's. (C) Mice were treated i.p. with $\alpha \mathrm{lL}-1 \mathrm{R}$ at $300 \mu \mathrm{g}$ on days 0, 2, 4, 6, and 8 ( $n=$ at least four). Control animals received appropriate isotype controls (Supplementary Table 2). Data represents one experiment. Tongues were harvested and damage quantified by toluidine blue+ staining on D11. Quantification of damage analyzed by ANOVA with Tukey's post hoc. (D) Staining by hematoxylin and eosin of sectioned tongues and quantification of neutrophils on day 11 following HNI in the ulcer boundary area. Images captured at $100 \mu \mathrm{M}$ and zoomed in at $50 \mu \mathrm{M}$. Data analyzed by ANOVA with Tukey's post hoc. Data shown as means $\pm \mathrm{SEM},\left({ }^{*} \mathrm{P}<0.05,{ }^{* \star} \mathrm{P}<0.01,{ }^{* \star \star} \mathrm{P}<0.001\right)$.

same knockout mice are at least partially protected from autoimmune disease through a dampened neutrophil response (60). Yet, during HNI-induced OM, expression of neutrophil chemokines was not diminished in Ill7ra ${ }^{-/-}$mice. In fact, Csf3, which encodes for G-CSF, was significantly enhanced in the absence of IL-17RA. Concomitantly, IL-1 $\alpha$ and IL- $1 \beta$ were overproduced in $1117 \mathrm{ra}^{-1-}$ mice compared to WT. The dysregulated IL-1 levels in the absence of IL-17RA appear partially responsible for the elevated PMNs since blocking of IL-
$1 \mathrm{R}$ led to a reduction, but not a complete loss, of neutrophilic cells in the lesion and lessening of OM-mediated damage. The interplay between IL-1 and IL-17 in OM does align with the role of these cytokines in other oral diseases including OPC, during which IL$1 \alpha$ in part controls the neutrophil response (33).

Prolonged exposure to neutrophils can lead to enhanced tissue damage. This is because neutrophils secrete a repertoire of proteases and enzymes such as MMPs, elastase, Cathepsin G, and MPO that damage tissue $(61,62)$. MPO is abundantly 
A
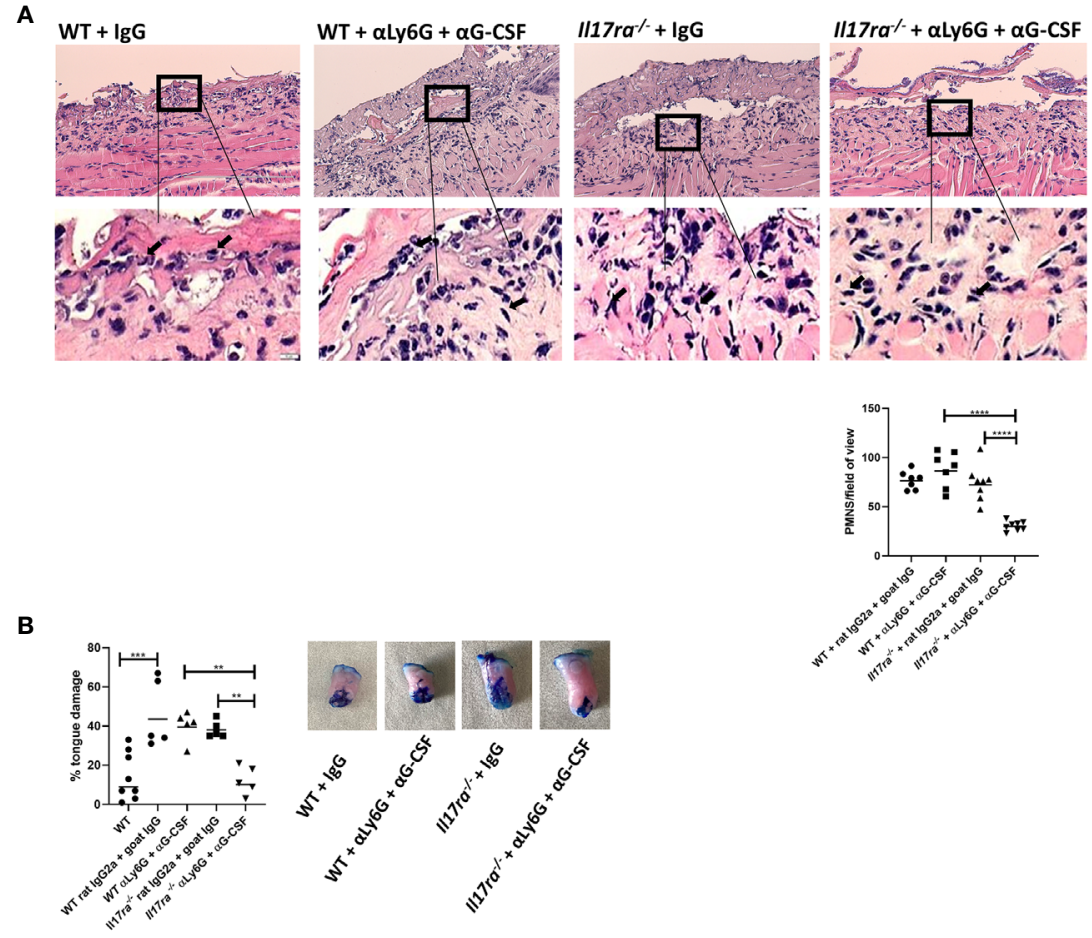

C

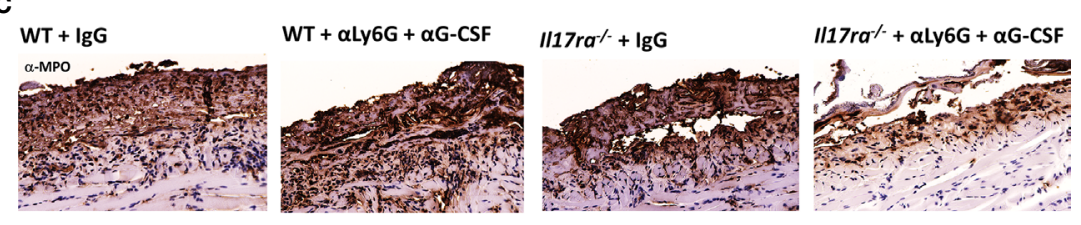

D

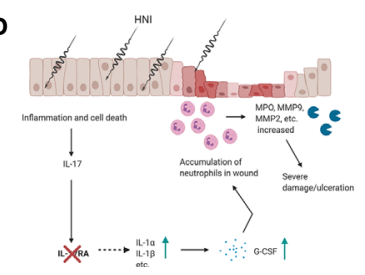

FIGURE 7 | Neutralization of neutrophils reduces damage in the absence of IL-17RA. Mice were treated i.p. with $\alpha$ Ly6G at $150 \mu g$ and $\alpha G-C S F$ at $10 \mu g$ ( $\mathrm{n}=5 /$ group) on day 7 following radiation. On days 8-10 mice were treated with $10 \mu \mathrm{g}$ of $\alpha \mathrm{G}$-CSF. Control animals received appropriate isotype controls (Supplementary Table 2). Data is representative of two independent experiments. (A) Staining by hematoxylin and eosin of sectioned tongues and quantification of neutrophils on day 11 following HNI. Images captured at 200 and $10 \mu \mathrm{M}$. Data analyzed by ANOVA with Tukey's post hoc. (B) Tongues were harvested and damage quantified by toluidine blue+ staining on D11. Data analyzed by ANOVA with Tukey's. (C) Representative MPO-staining of ulcer boundary counterstained with hematoxylin. (D) Proposed mechanism of IL-17RA-mediated protection and healing of OM. Radiation induces inflammation and apoptosis, increasing IL-23 expression. IL-23, in turn activates IL-17RA-mediated inflammation. In the absence of IL-17RA, IL-23, along with IL-1a synergizes to induce excess neutrophil chemokines like G-CSF resulting in accumulation of neutrophils in the damaged area. Increased neutrophils release proteases that further damage the wound and contribute to delayed wound healing. Image created using BioRender with permission. Data shown as means $\pm \mathrm{SEM},\left({ }^{\star \star *} \mathrm{P}<0.01,{ }^{\star \star \star} \mathrm{P}<0.001,{ }^{\star \star \star \star} \mathrm{P}<0.0001\right)$.

expressed in neutrophil granules and is associated with severe OM lesions $(45,63)$ and delayed wound healing (64). Neutrophils also produce various MMPs, such as MMP-9, which was detected at elevated levels in $1117 \mathrm{ra}^{-1-}$ mice, and is associated with tissue destruction during periodontal disease and OM $(65,66)$. While the action of MMPs triggered by DNA damage associated with ionizing radiation contributes to the ulceration of the oral mucosae, MMPs are also required to breakdown the ECM for healing. Therefore, regulation of this system is critical $(67,68)$. The pathogenic nature of excess PMNs in $I l 17 \mathrm{ra}^{-/-}$mice was substantiated by the efficacy of $\alpha$-Ly6G/-GCSF treatment that greatly reduced neutrophils in the lesion and led to a reduction in damage. Although, this therapy did not result in a reduction of PMNs or damage in WT mice. We speculate this could be due to the treatment schedule used, and modifications in dosing may result in the blocking of neutrophils 
in WT mice and therapeutic efficacy. Indeed, antibody-based depletion of neutrophils can be complicated (69). Another possibility is since expression of Csf3 was markedly increased in

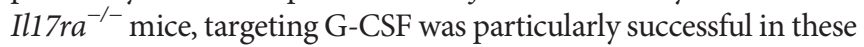
mice. Future studies to determine the potential of neutrophil blocking treatment in IL-17RA sufficient mice are warranted.

It is also important to consider that although oral ulcers in WT and $I l 17 \mathrm{ra}^{-/-}$mice started to heal at the same time, peak damage was more severe in mice deficient in IL-17RA (Supplementary Figure 1 and data not shown). This has important implications for patients that develop OM, since often it is the severity of disease that dictates termination or alteration of cancer therapies (2). It is critical to consider how the function of IL-17 in OM could also complicate targeting the Th17/IL-17 pathway to treat the associated malignancies. Because of the tumorigenic properties of IL-17 in the head and neck, it follows that the blockade of these cytokines in combination with other therapeutics might be efficacious in treating malignancies (70). However, our findings would indicate that antiIL-17 therapy exacerbates OM symptoms, complicating the therapeutic benefit of this strategy to fight head-neck cancers.

Our finding that treatment with $\alpha$-IL-17A antibody rendered mice as susceptible to $\mathrm{OM}$ as $1117 \mathrm{ra}^{-/-}$mice, may have implications for individuals receiving therapies that block Th17/IL-17 related immune components. Indeed, a rare case of lichenoid mucositis has been reported with secukinumab ( $\alpha$-IL17A monoclonal antibody) use (71). As the administration of anti-IL-17-related treatments increase, our study indicates that these patients should be monitored for development of mucositis. Susceptibility to severe OM is partly dependent on patient factors such as smoking and overall oral health at the start of treatment, while the genetic predispositions related to the incidence of $\mathrm{OM}$ are less understood. Genome-wide association studies have identified genomic loci pathways related to RTinduced OM, yet no associations with the Th17 cells or IL-17 have been identified (72). Further genomic studies considering other forms of cancer therapies may elucidate a role for IL-17 and other inflammatory pathways in $\mathrm{OM}$ and lead to better personalized treatment regiments (73).

In conclusion, we provide evidence that IL-17RA is important for protection during HNI-induced OM (Figure 7C). We propose that IL-17RA is critical for preventing excessive inflammation during the ulceration phase of OM. In the absence of IL-17RA other cytokines and chemokines that are in abundance amplify immune cell migration into the oral mucosae creating an environment of excessive inflammation and damage in the mucosal layer. Further, without IL-17RA a reduced proliferative capacity of the epithelium, along with increased apoptosis, leads to a breakdown in the maintenance of the mucosal layer. IL-17RA is necessary to prevent severe damage and promote healing after ionizing radiation, and this important contribution has implications for cancer therapies related to the Th17 pathway.

\section{DATA AVAILABILITY STATEMENT}

The datasets presented in this study can be found in online repositories. The names of the repository/repositories and accession number(s) can be found below: BioProject PRJNA720631, https:// www.ncbi.nlm.nih.gov/bioproject/PRJNA720631.

\section{ETHICS STATEMENT}

The animal study was reviewed and approved by the University of Toledo IACUC.

\section{AUTHOR CONTRIBUTIONS}

Conceptualization, Funding Acquisition and Projec Administration, HC. RNA-Seq computational analysis, VB, ACS, CM. FACS analysis, DL. Head-neck irradiation, EP and AL. Histology, AS, JS-M and JD. Experimental Support, JS-M, JD, JK, DL, EA, AW, GM, PB, and SC. Experimental Design, HC and JS-M. Paper writing, JS-M, EP and HC. All authors contributed to the article and approved the submitted version.

\section{FUNDING}

HC is supported for this work by a seed grant from Ohio Cancer Research and VB is supported by U19AI110820.

\section{ACKNOWLEDGMENTS}

We thank members of the Conti Lab for thoughtful discussion and critique of the manuscript. Katherine M.M. McKeone and Nathan Schmidt assisted with the head-neck irradiation of mice. Leah Wuescher provided technical expertise for imaging.

\section{SUPPLEMENTARY MATERIAL}

The Supplementary Material for this article can be found online at: https://www.frontiersin.org/articles/10.3389/fimmu.2021.687627/ full\#supplementary-material

Supplementary Figure 1 | WT mice exposed to radiation develop predictable OM stages (A). WT mice exposed to 22.5 Gy develop OM damage that peaks on Day 11 and is cleared by day 15. Data analyzed by ANOVA with Tukey's and represents at least 3 experiments (B). Solid lines depict the boundaries for considering what portion of the dorsal (top) tongue a lesion was found: proximal (near the excision-site), middle, or distal (tip of the tongue). Dashed line indicates where the tissue was portioned for RNA-seq analysis. Lesion location distribution in (C) WT mice $(n=51)$ and (D) //17ra -/- mice $(n=20)$. Data shown as means $+/$ - SEM, $\left({ }^{\star} \mathrm{P}<0.05,{ }^{\star \star} \mathrm{P}<0.01,{ }^{\star \star \star \star} \mathrm{P}<0.0001\right)$.

Supplementary Figure 2 | Changes in expression of IL-24 after exposure to HNI. Expression of II24 on D11 following radiation. Data pooled from at least 3 experiments and analyzed by ANOVA with Tukey's. Representative $\mathrm{IHC}$ images of IL-24 protein expression. Unfilled arrows represent negative staining while filled arrows represent positive staining. (C) Expression kinetics of $/ 1 \mathrm{a}$ and $/ 111 \mathrm{~b}$ following $\mathrm{HNI}$ assessed by qPCR. Results pooled from at least 3 experiments. Data shown as means + - SEM, $\left({ }^{\star} \mathrm{P}<0.05,{ }^{* \star} \mathrm{P}<0.01,{ }^{\star \star \star \star} \mathrm{P}<0.0001\right)$.

Supplementary Figure 3 | Gating strategy. (A) Gating strategy for neutrophils. (B) Gating strategy for necrosis, early apoptosis, and late apoptosis. 


\section{REFERENCES}

1. Basile D, Di Nardo P, Corvaja C, Garattini SK, Pelizzari G, Lisanti C, et al. Mucosal Injury During Anti-Cancer Treatment: From Pathobiology to Bedside. Cancers (Basel) (2019) 11(6):857-79. doi: 10.3390/cancers11060857

2. Lalla RV, Sonis ST, Peterson DE. Management of Oral Mucositis in Patients Who Have Cancer. Dent Clin North Am (2008) 52(1):61-77, viii. doi: 10.1016/ j.cden.2007.10.002

3. Sonis ST, Oster G, Fuchs H, Bellm L, Bradford WZ, Edelsberg J, et al. Oral Mucositis and the Clinical and Economic Outcomes of Hematopoietic StemCell Transplantation. J Clin Oncol (2001) 19(8):2201-5. doi: 10.1200/ JCO.2001.19.8.2201

4. Lalla RV, Latortue MC, Hong CH, Ariyawardana A, D’Amato-Palumbo S, Fischer DJ, et al. Fungal Infections Section Ocsgmaoscicisooo. A Systematic Review of Oral Fungal Infections in Patients Receiving Cancer Therapy. Support Care Cancer (2010) 18(8):985-92. doi: 10.1007/s00520-010-0892-z

5. Sroussi HY, Epstein JB, Bensadoun RJ, Saunders DP, Lalla RV, Migliorati CA, et al. Common Oral Complications of Head and Neck Cancer Radiation Therapy: Mucositis, Infections, Saliva Change, Fibrosis, Sensory Dysfunctions, Dental Caries, Periodontal Disease, and Osteoradionecrosis. Cancer Med (2017) 6(12):2918-31. doi: 10.1002/cam4.1221

6. Lionel D, Christophe L, Marc A, Jean-Luc C. Oral Mucositis Induced by Anticancer Treatments: Physiopathology and Treatments. Ther Clin Risk Manag (2006) 2(2):159-68. doi: 10.2147/tcrm.2006.2.2.159

7. Villa A, Sonis ST. An Update on Pharmacotherapies in Active Development for the Management of Cancer Regimen-Associated Oral Mucositis. Expert Opin Pharmacother (2020) 21(5):1-8. doi: 10.1080/14656566.2020.1718652

8. Maria OM, Eliopoulos N, Muanza T. Radiation-Induced Oral Mucositis. Front Oncol (2017) 7:89. doi: 10.3389/fonc.2017.00089

9. Naidu MU, Ramana GV, Rani PU, Mohan IK, Suman A, Roy P. Chemotherapy-Induced and/or Radiation Therapy-Induced Oral Mucositis-Complicating the Treatment of Cancer. Neoplasia (2004) 6 (5):423-31. doi: 10.1593/neo.04169

10. Sonis ST. A Biological Approach to Mucositis. J Support Oncol (2004) 2(1):2132; discussion 5-6.

11. Biswal BM. Current Trends in the Management of Oral Mucositis Related to Cancer Treatment. Malays J Med Sci (2008) 15(3):4-13

12. Bian L, Han G, Zhao CW, Garl PJ, Wang XJ. The Role of Smad7 in Oral Mucositis. Protein Cell (2015) 6(3):160-9. doi: 10.1007/s13238-014-0130-4

13. Scully C, Sonis S, Diz PD. Oral Mucositis. Oral Dis (2006) 12(3):229-41. doi: 10.1111/j.1601-0825.2006.01258.x

14. Ps SK, Balan A, Sankar A, Bose T. Radiation Induced Oral Mucositis. Indian J Palliat Care (2009) 15(2):95-102. doi: 10.4103/0973-1075.58452

15. Im KI, Nam YS, Kim N, Song Y, Lee ES, Lim JY, et al. Regulation of HMGB1 Release Protects Chemoradiotherapy-Associated Mucositis. Mucosal Immunol (2019) 12(5):1070-81. doi: 10.1038/s41385-019-0132-x

16. Yu JJ, Ruddy MJ, Wong GC, Sfintescu C, Baker PJ, Smith JB, et al. An Essential Role for IL-17 in Preventing Pathogen-Initiated Bone Destruction: Recruitment of Neutrophils to Inflamed Bone Requires IL-17 ReceptorDependent Signals. Blood (2007) 109(9):3794-802. doi: 10.1182/blood-200509-010116

17. Sun L, Girnary M, Wang L, Jiao Y, Zeng E, Mercer K, et al. Il-10 Dampens an IL-17-Mediated Periodontitis-Associated Inflammatory Network. J Immunol (2020) 204(8):2177-91. doi: 10.4049/jimmunol.1900532

18. Liu D, Zhang R, Wu J, Pu Y, Yin X, Cheng Y, et al. Interleukin-17A Promotes Esophageal Adenocarcinoma Cell Invasiveness Through ROS-Dependent, NF-Kappab-Mediated MMP-2/9 Activation. Oncol Rep (2017) 37(3):177985. doi: $10.3892 /$ or. 2017.5426

19. Brockmann L, Giannou AD, Gagliani N, Huber S. Regulation of TH17 Cells and Associated Cytokines in Wound Healing, Tissue Regeneration, and Carcinogenesis. Int J Mol Sci (2017) 18(5):1033-49. doi: 10.3390/ijms18051033

20. Wei T, Cong X, Wang XT, Xu XJ, Min SN, Ye P, et al. Interleukin-17A Promotes Tongue Squamous Cell Carcinoma Metastasis Through Activating miR-23b/versican Pathway. Oncotarget (2017) 8(4):6663-80. doi: 10.18632/ oncotarget.14255

21. Naher L, Kiyoshima T, Kobayashi I, Wada H, Nagata K, Fujiwara H, et al. STAT3 Signal Transduction Through interleukin-22 in Oral Squamous Cell Carcinoma. Int J Oncol (2012) 41(5):1577-86. doi: 10.3892/ijo.2012.1594
22. Whibley N, Gaffen SL. Gut-Busters: IL-17 Ain't Afraid of No Il-23. Immunity (2015) 43(4):620-2. doi: 10.1016/j.immuni.2015.10.001

23. Lee JS, Tato CM, Joyce-Shaikh B, Gulen MF, Cayatte C, Chen Y, et al. Interleukin-23-Independent IL-17 Production Regulates Intestinal Epithelial Permeability. Immunity (2015) 43(4):727-38. doi: 10.1016/j.immuni. 2015.09.003

24. Maxwell JR, Zhang Y, Brown WA, Smith CL, Byrne FR, Fiorino M, et al. Differential Roles for Interleukin-23 and Interleukin-17 in Intestinal Immunoregulation. Immunity (2015) 43(4):739-50. doi: 10.1016/j.immuni. 2015.08.019

25. Hadian Y, Bagood MD, Dahle SE, Sood A, Isseroff RR. Interleukin-17: Potential Target for Chronic Wounds. Mediators Inflammation (2019) 2019:1297675. doi: 10.1155/2019/1297675

26. Visan I. Inflammation and Wound Repair. Nat Immunol (2012) 13(10):939doi: 10.1038/ni.2435

27. Floudas A, Saunders SP, Moran T, Schwartz C, Hams E, Fitzgerald DC, et al. Il-17 Receptor A Maintains and Protects the Skin Barrier To Prevent Allergic Skin Inflammation. J Immunol (2017) 199(2):707-17. doi: 10.4049/jimmunol. 1602185

28. Ye P, Garvey PB, Zhang P, Nelson S, Bagby G, Summer WR, et al. Interleukin17 and Lung Host Defense Against Klebsiella Pneumoniae Infection. Am J Respir Cell Mol Biol (2001) 25(3):335-40. doi: 10.1165/ajrcmb.25.3.4424

29. Kim D, Langmead B, Salzberg SL. HISAT: A Fast Spliced Aligner With Low Memory Requirements. Nat Methods (2015) 12(4):357-60. doi: 10.1038/ nmeth. 3317

30. Anders S, Huber W. Differential Expression Analysis for Sequence Count Data. Genome Biol (2010) 11(10):R106. doi: 10.1186/gb-2010-11-10-r106

31. Bucher H, Mang S, Keck M, Przibilla M, Lamb DJ, Schiele F, et al. Neutralization of Both IL-1alpha/IL-1beta Plays a Major Role in Suppressing Combined Cigarette Smoke/Virus-Induced Pulmonary Inflammation in Mice. Pulm Pharmacol Ther (2017) 44:96-105. doi: 10.1016/j.pupt.2017.03.008

32. Kulig P, Musiol S, Freiberger SN, Schreiner B, Gyulveszi G, Russo G, et al. Il12 Protects From Psoriasiform Skin Inflammation. Nat Commun (2016) 7:13466. doi: $10.1038 /$ ncomms 13466

33. Altmeier S, Toska A, Sparber F, Teijeira A, Halin C, LeibundGut-Landmann S. Il-1 Coordinates the Neutrophil Response to C. albicans Oral Mucosa PloS Pathog (2016) 12(9):e1005882. doi: 10.1371/journal.ppat.1005882

34. Shi C, Penagaricano J, Papanikolaou N. Comparison of IMRT Treatment Plans Between Linac and Helical Tomotherapy Based on Integral Dose and Inhomogeneity Index. Med Dosim (2008) 33(3):215-21. doi: 10.1016/ j.meddos.2007.11.001

35. De Sanctis V, Merlotti A, De Felice F, Trignani M, Dell'Oca I, Lastrucci L, et al. Intensity Modulated Radiation Therapy and Oral Mucosa Sparing in Head and Neck Cancer Patients: A Systematic Review on Behalf of Italian Association of Radiation Oncology - Head and Neck Working Group. Crit Rev Oncol Hematol (2019) 139:24-30. doi: 10.1016/j.critrevonc.2019.04.022

36. Yang EJ, Beck KM, Liao W. Secukinumab in the Treatment of Psoriasis: Patient Selection and Perspectives. Psoriasis (Auckl) (2018) 8:75-82. doi: 10.2147/PTT.S146004

37. Maria OM, Syme A, Eliopoulos N, Muanza T. Single-Dose Radiation-Induced Oral Mucositis Mouse Model. Front Oncol (2016) 6:154. doi: 10.3389/ fonc. 2016.00154

38. Kuwabara T, Ishikawa F, Kondo M, Kakiuchi T. The Role of IL-17 and Related Cytokines in Inflammatory Autoimmune Diseases. Mediators Inflammation (2017) 2017:3908061. doi: 10.1155/2017/3908061

39. Marcussen M, Sonderkaer M, Bodker JS, Andersen M, Nielsen S, Vesteghem C, et al. Oral Mucosa Tissue Gene Expression Profiling Before, During, and After Radiation Therapy for Tonsil Squamous Cell Carcinoma. PloS One (2018) 13(1):e0190709. doi: 10.1371/journal.pone.0190709

40. Conti HR, Bruno VM, Childs EE, Daugherty S, Hunter JP, Mengesha BG, et al. Il-17 Receptor Signaling in Oral Epithelial Cells Is Critical for Protection Against Oropharyngeal Candidiasis. Cell Host Microbe (2016) 20(5):606-17. doi: 10.1016/j.chom.2016.10.001

41. Bodey GP, Buckley M, Sathe YS, Freireich EJ. Quantitative Relationships Between Circulating Leukocytes and Infection in Patients With Acute Leukemia. Ann Intern Med (1966) 64(2):328-40. doi: 10.7326/0003-481964-2-328 
42. Kishimoto M, Akashi M, Tsuji K, Kusumoto J, Furudoi S, Shibuya Y, et al. Intensity and Duration of Neutropenia Relates to the Development of Oral Mucositis But Not Odontogenic Infection During Chemotherapy for Hematological Malignancy. PloS One (2017) 12(7):e0182021. doi: 10.1371/ journal.pone.0182021

43. Lee HR, Yoo N, Kim JH, Sohn KY, Kim HJ, Kim MH, et al. The Therapeutic Effect of PLAG Against Oral Mucositis in Hamster and Mouse Model. Front Oncol (2016) 6:209. doi: 10.3389/fonc.2016.00209

44. Hong BY, Sobue T, Choquette L, Dupuy AK, Thompson A, Burleson JA, et al. Chemotherapy-Induced Oral Mucositis Is Associated With Detrimental Bacterial Dysbiosis. Microbiome (2019) 7(1):66. doi: 10.1186/s40168-0190679-5

45. Miyamoto H, Kanayama T, Horii K, Kawai T, Tsuchimochi T, Shigetomi T, et al. The Relationship Between the Severity of Radiation-Induced Oral Mucositis and the Myeloperoxidase Levels in Rats. Oral Surg Oral Med Oral Pathol Oral Radiol (2015) 120(3):329-36. doi: 10.1016/j.oooo.2015.04.012

46. Nakajima N, Watanabe S, Kiyoi T, Tanaka A, Suemaru K, Araki H. Evaluation of Edaravone Against Radiation-Induced Oral Mucositis in Mice. J Pharmacol Sci (2015) 127(3):339-43. doi: 10.1016/j.jphs.2015.02.001

47. Hao W, Li M, Zhang Y, Zhang C, Xue Y. Expressions of MMP-12, Timp-4, and Neutrophil Elastase in PBMCs and Exhaled Breath Condensate in Patients With COPD and Their Relationships With Disease Severity and Acute Exacerbations. J Immunol Res (2019) 2019:7142438. doi: 10.1155/2019/7142438

48. Krotova K, Khodayari N, Oshins R, Aslanidi G, Brantly ML. Neutrophil Elastase Promotes Macrophage Cell Adhesion and Cytokine Production Through the Integrin-Src Kinases Pathway. Sci Rep (2020) 10(1):15874. doi: 10.1038/s41598-020-72667-3

49. Caley MP, Martins VL, O'Toole EA. Metalloproteinases and Wound Healing. Adv Wound Care (New Rochelle) (2015) 4(4):225-34. doi: 10.1089/ wound.2014.0581

50. Armstrong DG, Jude EB. The Role of Matrix Metalloproteinases in Wound Healing. J Am Podiatr Med Assoc (2002) 92(1):12-8. doi: 10.7547/87507315-92-1-12

51. Kanarek N, Grivennikov SI, Leshets M, Lasry A, Alkalay I, Horwitz E, et al. Critical Role for IL-1beta in DNA Damage-Induced Mucositis. Proc Natl Acad Sci U S A (2014) 111(6):E702-11. doi: 10.1073/pnas.1322691111

52. Morales-Rojas T, Viera N, Moron-Medina A, Alvarez CJ, Alvarez A. Proinflammatory Cytokines During the Initial Phase of Oral Mucositis in Patients With Acute Lymphoblastic Leukaemia. Int J Paediatr Dent (2012) 22 (3):191-6. doi: 10.1111/j.1365-263X.2011.01175.x

53. de Mooij CEM, Netea MG, van der Velden W, Blijlevens NMA. Targeting the Interleukin-1 Pathway in Patients With Hematological Disorders. Blood (2017) 129(24):3155-64. doi: 10.1182/blood-2016-12-754994

54. Aggor FEY, Break TJ, Trevejo-Nunez G, Whibley N, Coleman BM, Bailey RD, et al. Oral Epithelial IL-22/STAT3 Signaling Licenses IL-17-Mediated Immunity to Oral Mucosal Candidiasis. Sci Immunol (2020) 5(48): eaba0570. doi: 10.1126/sciimmunol.aba0570

55. Shetty S, Gokul S. Keratinization and its Disorders. Oman Med J (2012) 27 (5):348-57. doi: 10.5001/omj.2012.90

56. Gaffen SL, Moutsopoulos NM. Regulation of Host-Microbe Interactions at Oral Mucosal Barriers by Type 17 Immunity. Sci Immunol (2020) 5(43): eaau4594. doi: 10.1126/sciimmunol.aau4594

57. Moutsopoulos NM, Zerbe CS, Wild T, Dutzan N, Brenchley L, DiPasquale G, et al. Interleukin-12 and Interleukin-23 Blockade in Leukocyte Adhesion Deficiency Type 1. N Engl J Med (2017) 376(12):1141-6. doi: 10.1056/NEJMoa1612197

58. Semerad CL, Liu F, Gregory AD, Stumpf K. Link DC. G-CSF Is an Essential Regulator of Neutrophil Trafficking From the Bone Marrow to the Blood. Immunity (2002) 17(4):413-23. doi: 10.1016/s1074-7613(02)00424-7

59. Mengesha BG, Conti HR. The Role of IL-17 in Protection Against Mucosal Candida Infections. J Fungi (Basel) (2017) 3(4):52-64. doi: 10.3390/ jof3040052

60. Croxford AL, Karbach S, Kurschus FC, Wortge S, Nikolaev A, Yogev N, et al. IL-6 Regulates Neutrophil Microabscess Formation in IL-17A-Driven
Psoriasiform Lesions. J Invest Dermatol (2014) 134(3):728-35. doi: 10.1038/ jid.2013.404

61. Aratani Y. Myeloperoxidase: Its Role for Host Defense, Inflammation, and Neutrophil Function. Arch Biochem Biophys (2018) 640:47-52. doi: 10.1016/ j.abb.2018.01.004

62. Wilgus TA, Roy S, McDaniel JC. Neutrophils and Wound Repair: Positive Actions and Negative Reactions. Adv Wound Care (New Rochelle) (2013) 2 (7):379-88. doi: 10.1089/wound.2012.0383

63. Mafra C, Vasconcelos RC, de Medeiros C, Leitao RFC, Brito GAC, Costa D, et al. Gliclazide Prevents 5-Fu-Induced Oral Mucositis by Reducing Oxidative Stress, Inflammation, and P-Selectin Adhesion Molecules. Front Physiol (2019) 10:327. doi: 10.3389/fphys.2019.00327

64. Gabr SA, Alghadir AH. Evaluation of the Biological Effects of Lyophilized Hydrophilic Extract of Rhus Coriaria on Myeloperoxidase (Mpo) Activity, Wound Healing, and Microbial Infections of Skin Wound Tissues. Evid Based Complement Alternat Med (2019) 2019:5861537. doi: 10.1155/2019/5861537

65. Makela M, Salo T, Uitto VJ, Larjava H. Matrix Metalloproteinases (MMP-2 and MMP-9) of the Oral Cavity: Cellular Origin and Relationship to Periodontal Status. J Dent Res (1994) 73(8):1397-406. doi: 10.1177/ 00220345940730080201

66. Al-Azri AR, Gibson RJ, Bowen JM, Stringer AM, Keefe DM, Logan RM. Involvement of Matrix Metalloproteinases (MMP-3 and MMP-9) in the Pathogenesis of Irinotecan-Induced Oral Mucositis. J Oral Pathol Med (2015) 44(6):459-67. doi: 10.1111/jop.12255

67. McCarty SM, Percival SL. Proteases and Delayed Wound Healing. Adv Wound Care (New Rochelle) (2013) 2(8):438-47. doi: 10.1089/ wound.2012.0370

68. Lindsay S, Oates A, Bourdillon K. The Detrimental Impact of Extracellular Bacterial Proteases on Wound Healing. Int Wound J (2017) 14(6):1237-47. doi: 10.1111/iwj.12790

69. Boivin G, Faget J, Ancey P-B, Gkasti A, Mussard J, Engblom C, et al. Durable and Controlled Depletion of Neutrophils in Mice. Nat Commun (2020) 11:2762. doi: 10.1038/s41467-020-16596-9

70. Wang K, Kim MK, Di Caro G, Wong J, Shalapour S, Wan J, et al. Interleukin17 Receptor a Signaling in Transformed Enterocytes Promotes Early Colorectal Tumorigenesis. Immunity (2014) 41(6):1052-63. doi: 10.1016/ j.immuni.2014.11.009

71. Thompson JM, Cohen LM, Yang CS, Kroumpouzos G. Severe, Ulcerative, Lichenoid Mucositis Associated With Secukinumab. JAAD Case Rep (2016) 2 (5):384-6. doi: 10.1016/j.jdcr.2016.07.009

72. Yang DW, Wang TM, Zhang JB, Li XZ, He YQ, Xiao R, et al. Genome-Wide Association Study Identifies Genetic Susceptibility Loci and Pathways of Radiation-Induced Acute Oral Mucositis. J Transl Med (2020) 18(1):224. doi: 10.1186/s12967-020-02390-0

73. Reyes-Gibby CC, Melkonian SC, Wang J, Yu RK, Shelburne SA, Lu C, et al. Identifying Novel Genes and Biological Processes Relevant to the Development of Cancer Therapy-Induced Mucositis: An Informative Gene Network Analysis. PloS One (2017) 12(7):e0180396. doi: 10.1371/ journal.pone.0180396

Conflict of Interest: The authors declare that the research was conducted in the absence of any commercial or financial relationships that could be construed as a potential conflict of interest.

Copyright (c) 2021 Saul-McBeth, Dillon, Lee, Launder, Kratch, Abutaha, Williamson, Schroering, Michalski, Biswas, Conti, Shetty, McCracken, Bruno, Parsai and Conti. This is an open-access article distributed under the terms of the Creative Commons Attribution License (CC BY). The use, distribution or reproduction in other forums is permitted, provided the original author(s) and the copyright owner(s) are credited and that the original publication in this journal is cited, in accordance with accepted academic practice. No use, distribution or reproduction is permitted which does not comply with these terms. 